
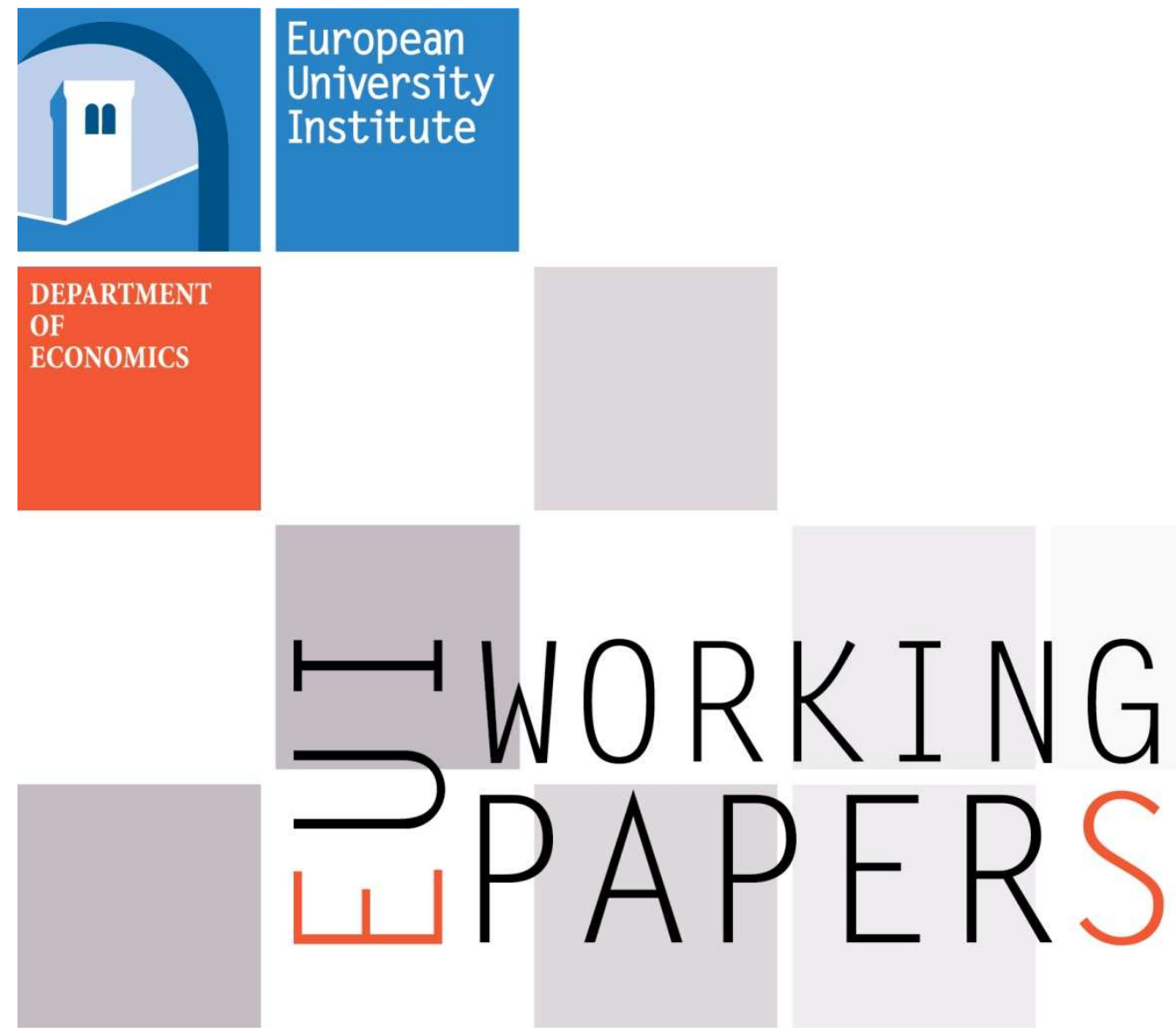

ECO 2014/04

Department of Economics

DONATIONS, RISK ATTITUDES AND TIME PREFERENCES: A STUDY ON ALTRUISM IN PRIMARY SCHOOL CHILDREN

Silvia Angerer, Daniela Glätzle-Rützler, Philipp Lergetporer and Matthias Sutter 

European University Institute

Department of Economics

Donations, Risk Attitudes and Time Preferences: A Study on Altruism in Primary School Children

Silvia Angerer, Daniela Glätzle-Rützler, Philipp Lergetporer and Matthias Sutter

EUI Working Paper ECO 2014/04 
This text may be downloaded for personal research purposes only. Any additional reproduction for other purposes, whether in hard copy or electronically, requires the consent of the author(s), editor(s). If cited or quoted, reference should be made to the full name of the author(s), editor(s), the title, the working paper or other series, the year, and the publisher.

ISSN 1725-6704

(c) Silvia Angerer, Daniela Glätzle-Rützler, Philipp Lergetporer and Matthias Sutter , 2014

Printed in Italy

European University Institute

Badia Fiesolana

I - 50014 San Domenico di Fiesole (FI)

Italy

www.eui.eu

cadmus.eui.eu 



\title{
Donations, risk attitudes and time preferences: A study on altruism in primary school children*
}

\author{
Silvia Angerer ${ }^{\dagger}$ \\ University of Innsbruck \\ Daniela Glätzle-Rützler \\ University of Innsbruck \\ Philipp Lergetporer \\ University of Innsbruck and Ifo Institute at the University of Munich \\ Matthias Sutter \\ European University Institute and University of Cologne
}

We study with a sample of 1,070 primary school children, aged seven to eleven years, how altruism in a donation experiment is related to children's risk attitudes and intertemporal choices. Examining such a relationship is motivated by theories of reciprocal altruism that provide a cornerstone to understand human social behavior. We find that higher risk tolerance and patience in intertemporal choice increase, in general, the level of donations, albeit the effects are non-linear. We confirm earlier results that altruism increases with age during childhood and that girls are more altruistic than boys. Having older brothers makes subjects less altruistic.

JEL-Code C91, D03, D63, D64

Keywords Altruism, donations, risk attitudes, intertemporal choices, experiment, children

27 January 2014

\footnotetext{
We are particularly grateful to Fabian Kosse, Hanna Schildberg-Hörisch, and participants at the Workshop of Self-Control, Self-Regulation and Education at Aarhus University for very helpful comments. We thank Rudolf Meraner from the South Tyrolean State Board of Education (Pädagogisches Institut für die deutsche Sprachgruppe in Südtirol), the schools' headmasters (Gabriella Kustatscher, Maria Angela Madera, Eva Dora Oberleiter, Brigitte Öttl, Ursula Pulyer, Vally Valbonesi), and the parents of the involved children for making this study possible, and the children for participation. Financial support from the Government of the autonomous province South Tyrol is gratefully acknowledged.

† Corresponding author's address: Department of Public Finance, University of Innsbruck, Universitätsstraße 15, A-6020 Innsbruck, Austria. Phone: +43(0)5125077162. E-mail: silvia.angerer@uibk.ac.at
} 


\section{Introduction}

Non-selfish, other-regarding behavior is an important prerequisite for cooperation in human societies where large numbers of genetically unrelated strangers interact with each other. This means that such behavior is a lubricant for the well-functioning of institutions, markets and societies as a whole (Bowles, 2004; Boyd and Richardson, 2005).

Despite that, the reasons for other-regarding preferences towards genetically unrelated strangers have been under close scientific scrutiny for decades. A fundamental contribution for a better understanding of the roots of other-regarding behavior has been provided by Trivers (1971) who argues that cooperation among non-kin can be maintained at high levels through reciprocal altruism. An individual engages in reciprocal altruism if she foregoes immediate benefits by acting altruistically towards another person in the expectation of receiving a larger payoff from the interaction partner in return later. Such behavior is frequently observed in humans (Fehr and Gächter, 2000), but it obviously involves a component that is related to intertemporal choices, because altruism is expected to pay off at some time in the future only while the costs of it have to be borne now. Individuals with higher discount rates of future rewards can therefore be expected to engage less in altruistic behavior than more patient individuals (Axelrod, 1984). This will be the first hypothesis tested in this paper.

Apart from patience, risk preferences are potentially important for reciprocal altruism. If an individual helps another subject hoping to be repaid later, the individual has to bear the risk that the other subject is not going to reciprocate in the future. From this it follows that more risk averse individuals should be less likely to engage in reciprocal altruism. This will be studied as our second hypothesis.

Our setting to study our hypotheses involves more than 1,000 primary school children in the bilingual city of Meran in Italy. The children are seven to eleven years old and represent $86 \%$ of all primary school children in this city with its 38,000 inhabitants. We let children decide in a dictator-game like framework how many experimental tokens they want to keep for themselves and how many they want to donate to a well-known charity in this part of Italy. While the determinants of donations have been extensively studied with adults (List, 2011), we can examine which factors influence children's altruistic giving to needy recipients. Of course, our paper is also related to previous work on how altruism develops in childhood. Both psychologists and economists are interested in this issue (see Eisenberg and Fabes, 1998, for a review from the perspective of developmental psychology). The common bottom-line seems to be the insight that altruism develops and gets stronger in childhood. In other words, 
the evidence from dictator, ultimatum and trust games suggests that humans become less selfish as they grow older (Murnighan and Saxon, 1998; Harbaugh and Krause, 2000; Harbaugh et al., 2003; Benenson et al., 2007; Sutter and Kocher, 2007; Fehr et al., 2008; Gummerum et al., 2008, 2010). However, none of these previous studies has addressed how pro-social behavior in the various bargaining games or allocation tasks relates to risk attitudes and intertemporal choices. For this reason we are contributing to this literature on social preferences and their development during childhood by examining the hypotheses outlined above. In addition to testing the relation of pro-social behavior to risk attitudes and intertemporal choices, our dataset allows us to study the effects of socio-demographic variables such as the children's IQ, the number of siblings and measures for the socioeconomic status and education of their parents.

Our results suggest a significant, yet largely non-linear, relation between altruism in our donation experiment and risk tolerance respectively patience. Altruism increases with age, a finding that confirms previous studies. Girls are more generous in their donations, and so are subjects with a higher relative IQ. Having older brothers reduces donations, while fathers with higher education induce (weakly) larger donations. We find no difference in the donations of Italian- and German-speaking children.

The rest of the paper is structured as follows: The next section describes the experimental design. The results are presented in Section 3 and Section 4 concludes the paper.

\section{Experimental Design}

The experiments were conducted in October and November 2012 in the city of Meran in the province of South Tyrol, Italy. This city provides an almost unique natural setting since half of its 38,000 inhabitants is German-speaking and the other half speaks Italian. Schools are segregated by language, despite serving children from the same neighborhoods. This enables us to assess whether the language spoken influences the children's attitudes towards altruism. ${ }^{1}$ In total, 1,070 children, aged seven to eleven years and attending grades two to five of the primary schools in the city, participated in the experiment. Table 1 indicates the number of subjects per grade, gender and language spoken.

\section{Table 1 about here}

\footnotetext{
${ }^{1}$ In a recent study, Chen (2013) shows that languages with strong future tense reference (like Italian) induce less future-oriented economic behavior than languages with weak future tense reference (like German). Thus, it is sensible to test whether this language-effect extends to other dimensions of economic behavior such as distributional preferences.
} 
As one central aspect of this study is to investigate the connections between altruism and other dimensions of experimentally elicited economic behavior, we used the same subject pool to run experiments on altruism, risk attitudes and intertemporal choices. All experiments were incentivized with tokens which could be exchanged for fruits, sweets and other little presents by the decision maker. ${ }^{2}$ All of these experiments were part of a larger research project on the development of economic decision making of primary school children. By visiting the same students several times in the course of two academic years, they were generally familiar with experimental procedures and that sometimes rewards could only be distributed after a temporary delay (for instance in experiments on intertemporal choices or in strategic games where the matching needed to be done manually after an experiment).

\subsection{The donation game}

We employed the following dictator game-like experiment on donations to a charity: Each child received an endowment of six tokens and was asked to allocate them between him- or herself and a needy recipient. The decision maker could exchange the retained tokens for little presents right after the experiment. The cash equivalent of the donated tokens was transferred to one of the province's largest charities - called "Menschen in Not: Kinderarmut durch Kinderreichtum - Umanità che ha bisogno: famiglia numerosa = famiglia povera?", an initiative to support underprivileged children in South Tyrol. This charity is run by the wellknown Caritas diocese Bolzano-Bressanone. For each token donated the charity received 50 cents. Subjects were not informed about the exact cash value of the tokens. Instead, we told them that one token was converted into the monetary value it buys on average in the experimental shop (which was 50 Euro-cents). In total, 951.50 Euro were donated to the charity.

As we used a one-on-one explanation for assuring comprehension, experimenter demand effects may affect our results. In order to minimize that, children were asked to allocate their endowment between a grey envelope (for them) and a white envelope (for the needy child) and seal them in private. ${ }^{3}$ Each subject was instructed to insert the white envelope (with the donation) into a donation box which was located in the middle of the room. ${ }^{4}$ At the end of the experiment, each child took his or her grey envelope and was escorted to another room in

\footnotetext{
${ }^{2}$ Experimental instructions of all experiments are provided in Appendix A.

${ }^{3}$ In order to assure privacy while not violating custody, the experimenter turned around until the child indicated that the task was completed.

${ }^{4}$ Children were instructed to do so even if the white envelope was empty.
} 
which the experimental shop was set up where children could exchange the retained tokens into presents. Children entered the experimental shop one-by-one in order to guarantee anonymity of decisions towards other children. An experimenter in the shop (different from the one running the experiment with the child) then let the child exchange the tokens in the grey envelope into presents.

\subsection{Elicitation of risk attitudes}

Risk attitudes were elicited with a simple investment task in the same experimental session. In this task, each child was endowed with five tokens and had to decide how many of these tokens to invest in a lottery that doubled the number of invested tokens with a $50 \%$ probability, while with $50 \%$ probability the child lost its investment (this follows the design of Charness and Gneezy, 2010). Non-invested tokens were safe earnings for the child. We take the number of invested tokens as an indicator of risk-tolerance.

\subsection{Elicitation of intertemporal choices}

In this experiment children were endowed with five tokens and they had to decide how many tokens to consume immediately (by exchanging them into small presents) and how many tokens to invest into the future. Each invested token was doubled and paid out only four weeks after the experiment. In the case of delayed payments, the classroom teacher delivered the presents to the children in sealed envelopes exactly four weeks after the experiment. The intertemporal choice experiment was run with the same subject pool about one month after the other two experiments.

\section{Results}

\subsection{Descriptive analysis}

Figure 1 shows the distribution of donations across age cohorts. Due to the low incidence of 4, 5 and 6 donations, we pooled subjects who donated more than half of their endowment. We find that the share of subjects deciding to donate zero tokens decreases monotonically from $29 \%$ for $7 / 8$-year-olds to $13 \%$ for $10 / 11$-year-olds. This decreasing trend is statistically significant $(p<0.01$, Cuzick's Wilcoxon-type test for trend). While the share of subjects who donate one, two or three tokens remains constant at about 30\%, 20-25\% and 20\%, respectively, the fraction of subjects giving more than half of their endowment increases significantly with age ( $p<0.01$, Cuzick's Wilcoxon-type test for trend), albeit it remains fairly small. Taken together, these observations indicate that altruism increases with age. 


\section{Figure 1 about here}

Apart from age effects, Figure 1 reveals a high degree of heterogeneity in donations within each age group. Hence, we investigate in a next step the effects of additional individual-specific characteristics that may explain the potential sources of this variation.

In panel (a) of Figure 2 we show the relative frequency of donations, conditional on risk tolerance as measured by our investment task. The width of the different columns represents the relative frequency with which children invested from zero to five tokens into the lottery. Moving to the right along the horizontal axis indicates more risk tolerance, therefore. The data suggests a negative relationship between risk taking and the probability of donating zero tokens for low levels of risk tolerance (up to 3 tokens invested), but a positive relation for high levels of risk tolerance (from 3 to 5 tokens). A reversed non-linear pattern can be observed for donating two or more tokens. Thus, children with intermediate risk attitudes are less likely to donate zero tokens and more likely to give more of their endowment as compared to subjects with relatively extreme risk attitudes.

The relationship between donations and patience is illustrated in panel (b), with columns again indicating the relative frequency with which children invested a particular amount of tokens into the future (to get two presents per token in four weeks). There is a significant relationship between patience and the likelihood of donating money to the charity. More patient subjects are significantly less likely to retain all the tokens for themselves $(p<0.01$; Cuzick's Wilcoxon-type test for trend). The overall level of donations is also significantly increasing with patience ( $p<0.01$; Cuzick's Wilcoxon-type test for trend). However, the impact of patience on donations resembles the pattern of risk tolerance by showing a nonlinear relationship: Very impatient and very patient children are less likely to donate two or more tokens than children who invest an intermediate amount of tokens.

\section{Figure 2 about here}

Figure 3 displays the average donations across age and gender, showing that girls donate significantly more $(p<0.01$ across all age groups, Wilcoxon Rank Sum Test). Moreover, Figure 3 confirms the well-established finding that children become more altruistic as they become older $(p<0.01$ for both genders, Cuzick's Wilcoxon-type test for trend). It is 
furthermore noteworthy that the donation rates of our oldest subjects are similar to the share usually observed in adults whereas the youngest children give significantly less ${ }^{5}$.

\section{Figure 3 about here}

\subsection{Regression analysis}

In order to explore further determinants of non-selfish behavior we present in Table 2 a regression analysis with the number of donated tokens as the dependent variable. Model (1) shows the basic model with dummies for being female, being a member of the German language group, for the participant's age in years, as well as an only child dummy as explanatory variables. Besides replicating the effects of gender and age as discussed in our descriptive analysis, we find that only children donate more tokens. We disentangle this effect by including detailed background information on siblings as dependent variables in Model (2) and find that the number of older brothers is driving the result. ${ }^{6}$

We measured children's IQ with Raven's "Colored Progressive Matrices" as a proxy for cognitive abilities. We find that higher IQ - relative to the grade's average - is associated with larger donations, as shown in Model (3). This finding fits to the study of Houser and Schunk (2009) who found that children with good mathematics grades are more generous. In addition, this model indicates that risk tolerance and patience affect donations in a non-linear way. One possible explanation for this non-linear trend might be that children with "extreme" risk attitudes and time preferences are also more likely to exhibit an "extreme" choice of giving zero in the donation experiment. To test whether the non-linear trend is driven by subjects who are either very patient (risk averse) or very impatient (risk tolerant) and give nothing at the same time, we ran another ordered probit regression (not shown here) and exclude subjects who donated zero tokens. This "extremist"-explanation is not supported by our data, however: The results reveal that risk tolerance as well as patience are still significantly and non-linearly related to the number of tokens donated.

In Models (4) and (5) we also take into account parent's occupation and use this information as a proxy for parents' unemployment status, income and education ${ }^{7}$ in order to control for the socioeconomic status of children's parents. The model shows that parental

\footnotetext{
${ }^{5}$ In his meta-analysis, Engel (2011) finds that adult subjects usually give away about thirty percent of their endowment.

${ }^{6}$ Fehr et al. (2008) report the same effects for only children and show that older siblings are more altruistic. Our results are aligned with their findings, providing a refined analysis for the effects of older sisters and brothers.

${ }^{7}$ See the Appendix on how we measured these attributes of parents.
} 
unemployment has no effect on donations whereas the level of education of the father is marginally significant and positively related to donations. ${ }^{8}$

\section{Table 2 about here}

\section{Conclusion}

In this paper we study the determinants of donations by children to a charity. We control for a host of background variables and in particular we are interested in the relationship of risk attitudes and time preferences with donations. While the existence of other-regarding preferences and their economic significance have been established in many studies over the past decades, the relationship with other economically important preferences such as risk- and time preferences has not been directly tested in children. As argued in the introduction, we expected larger donations of children who are more risk tolerant and more patient. Based on experiments with more than 1,000 primary school children, we have found some, but not unequivocal support for our hypotheses. In fact, we find that more patient children donate more tokens, in line with our hypothesis on the relationship with time preferences. However, the relationship is non-linear, both for risk attitudes and time preferences. Up to an intermediate level of risk tolerance and patience, donations increase, as expected. Yet, at the upper tail of risk tolerance and patience, donations decrease again, a finding which requires further exploration. One possible conjecture - that these non-linear findings would not be robust to considering only positive donations (and thus excluding all subjects who donate nothing) - has failed to provide an explanation, so more work is needed. Despite this, we consider it important to have shown that there is a relationship between risk attitudes, time preferences and altruism, the latter measured in a simple, and incentivized, donation experiment.

In addition to this finding, we show that the positive age trend in altruism can be attributed to the fact that the relative share of subjects who retain the whole pie decreases with age while the willingness to offer more than half of the endowment increases. Moreover, we find that the heterogeneity of preferences within different age groups can be explained by several factors: First, our analysis reveals that girls are significantly more generous than boys.

\footnotetext{
${ }^{8}$ Including the variables on the parent's education and income decreases our sample size to 679 observations. The reason for this is that it was not possible to obtain this information for all subjects. A post estimation Wald test on the joint effect of the education and income of the children's parents on the number of tokens donated turns out to be significant $(p<0.05)$. This suggests that the socioeconomic status has an overall effect on altruistic giving in the donations experiment. This is in line with the findings of Benenson et al. (2007).
} 
Second, we replicate the result that the number of siblings has a negative impact on dictator offers (see Fehr et al., 2008) and find that this effect can be attributed to older brothers. Third, our analysis reveals that children with higher IQ-test scores relative to their peers donate more tokens. Finally, we see a weak influence of a father's educational attainments on the generosity of children in our donation experiment. 


\section{References}

Axelrod, R., 1984. The evolution of cooperation. New York: Basic Books.

Benenson, J. F., Pascoe, J., Radmore, N., 2007. Children's Altruistic Behavior in the Dictator Game. Evolution and Human Behavior 28, 168-175.

Bowles, S., 2004. Microeconomics: Behavior, Institutions and Evolution. Princeton University Press.

Boyd, R. T., Richerson, R. J., 2005. The Origin and Evolution of Cultures. Oxford University Press. Oxford.

Charness, G., Gneezy, U, 2010. Portfolio Choice and Risk Attitudes: An Experiment. Economic Enquiry 48, 133-146.

Chen, M. K., 2013. The effect of language on economic behavior: Evidence from savings rates, health behaviors, and retirement assets: Dataset. American Economic Review 103, 690-731.

Eisenberg, N., Fabes, R. A. (1998). Prosocial development. In W. Damon, \& N. Eisenberg (Eds.), Handbook of child psychology: Vol. 3. Social, emotional, and personality development (pp. 701-778). New York, Wiley.

Engel, C., 2011. Dictator games: a meta study. Experimental Economics 14, 583-610.

Fehr, E., Bernhard, H., Rockenbach B., 2008. Egalitarianism in young children. Nature 454, 1079-1083.

Fehr, E., Gächter, S., 2000. Fairness and retaliation: The economics of reciprocity. Journal of Economic Perspectives 14, 159-181.

Gummerum, M., Hanoch, Y., Keller, M., Parsons, K., Hummel, A., 2010. Preschoolers‘ allocations in the dictator game. The role of moral emotions. Journal of Economic Psychology 31, 25-34.

Gummerum, M., Keller, M., Takezawa, M., Mata, J., 2008. To give or not to give: Children's and adolescents' sharing and moral negotiations in economic decision situations. Child Development 79, 561-576.

Harbaugh, W. T., Krause, K., 2000. Children's altruism in public good and dictator experiments. Economic Inquiry 38, 95-109.

Harbaugh, W. T., Krause, K., Liday, S. G., 2003. Bargaining by children. Unpublished manuscript, University of Oregon.

Houser, D., Schunk, D., 2009. Social environments with competitive pressure: Gender effects in the decisions of German schoolchildren. Journal of Economic Psychology 30, 634-641. 
List, J.A., 2011. The market for charitable giving. Journal of Economic Perspectives 25, 157 180.

Murnighan, J. K., Saxon, M. S., 1998. Ultimatum bargaining by children and adults. Journal of Economic Psychology 19, 415-445.

Sutter, M., Kocher, M. 2007. Trust and trustworthiness across different age groups. Games and Economic Behavior 59, 364-382.

Trivers, R. L., 1971. The evolution of reciprocal altruism. The Quarterly Review of Biology $46,35-57$. 


\section{Tables and Figures}

Table 1. Number of subjects participating in the experiment on altruism, by age, language and gender (number of male participants in parenthesis)

\begin{tabular}{lccc}
\hline \hline Age (in years) & Italian & German & Total \\
\hline $7 / 8$ years & $147(75)$ & $113(63)$ & $260(138)$ \\
$8 / 9$ years & $145(81)$ & $125(76)$ & $270(157)$ \\
$9 / 10$ years & $132(77)$ & $144(72)$ & $276(149)$ \\
$10 / 11$ years & $157(81)$ & $107(62)$ & $264(143)$ \\
\hline ALL & $\mathbf{5 8 1 ( 3 1 4 )}$ & $\mathbf{4 8 9}(\mathbf{2 7 3})$ & $\mathbf{1 , 0 7 0}$ \\
& & & $\mathbf{( 5 8 7 )}$
\end{tabular}

Each subject was asked to repeat the instructions in own words in order to check for understanding. 14 subjects were not able to do so properly, and we exclude them from the analysis. Moreover, 33 other children are excluded because they had close ties to the charity, either by relatives working there or by receiving transfers from the charity. 
Table 2. Number of tokens donated to needy recipient $(\min =0 ; \max =6)$. Ordered probit regressions.

Female $(=1)$

German school (=1)

Age (in years)

Only child (=1)

Number of younger brothers

Number of older brothers

Number of younger sisters

Number of older sisters

Patience $^{\&}$

Patience $^{2}$

Risk tolerance $^{\dagger}$

Risk tolerance ${ }^{2}$

Relative IQ Q $^{\$}$

Father unemployed $(=1)$

Mother unemployed (=1)

Income father ${ }^{\S}$

Income mother ${ }^{\S}$

Education father ${ }^{\S}$

Education mother $^{\S}$

cut1

Constant

cut2

Constant

cut3

Constant

cut4

Constant

cut5

Constant

\begin{tabular}{ccccc}
$(1)$ & $(2)$ & $(3)$ & $(4)$ & $(5)$ \\
\hline $0.314 * * *$ & $0.319^{* * *}$ & $0.335^{* * *}$ & $0.348^{* * *}$ & $0.338^{* * *}$ \\
$(0.063)$ & $(0.063)$ & $(0.061)$ & $(0.064)$ & $(0.077)$ \\
-0.052 & -0.051 & -0.102 & -0.117 & -0.097 \\
$(0.076)$ & $(0.076)$ & $(0.082)$ & $(0.086)$ & $(0.094)$ \\
$0.110^{* * *}$ & $0.114 * * *$ & $0.082^{* *}$ & $0.105 * * *$ & $0.106^{* * *}$ \\
$(0.031)$ & $(0.031)$ & $(0.033)$ & $(0.035)$ & $(0.039)$
\end{tabular}

0.178 *

(0.099)

$\begin{array}{cccc}-0.071 & -0.031 & -0.053 & -0.090 \\ (0.068) & (0.069) & (0.073) & (0.096) \\ -0.128 * * & -0.122 * * & -0.118^{* *} & -0.133^{*} \\ (0.056) & (0.057) & (0.060) & (0.077) \\ -0.076 & -0.058 & -0.027 & -0.020 \\ (0.065) & (0.072) & (0.077) & (0.091) \\ -0.040 & -0.040 & -0.052 & -0.075 \\ (0.047) & (0.048) & (0.053) & (0.075) \\ & 0.275^{* * *} & 0.245 * * * & 0.268 * * * \\ & (0.064) & (0.069) & (0.084) \\ & -0.0523 * * * & -0.050^{* * *} & -0.061 * * * \\ & (0.012) & (0.013) & (0.016) \\ & 0.598 * * * & 0.585 * * * & 0.684 * * * \\ & (0.130) & (0.151) & (0.190) \\ & -0.103 * * * & -0.101 * * * & -0.113 * * * \\ & (0.024) & (0.027) & (0.035) \\ & 0.310 * & 0.439 * * & 0.325 \\ & (0.189) & (0.201) & (0.250)\end{array}$

0.265

$(0.235)$

0.450

(0.394)

$-0.0001$

$(0.0001)$

$-0.0001$

(0.0002)

$0.085^{*}$

$(0.051)$

0.078

$(0.070)$

0.158

0.057

$0.931 * * *$

$1.192 * * *$

$1.058^{* *}$

(0.252)

(0.251)

(0.361)

(0.369)

(0.521)

$$
\begin{array}{cc}
1.063 * * * & 0.964 * * * \\
(0.254) & (0.254)
\end{array}
$$

$1.908 * * *$

$2.194 * * *$

$2.107^{* * *}$

(0.366)

(0.375)

(0.519)

$$
\begin{gathered}
1.747 * * * \\
(0.256)
\end{gathered}
$$

$1.650 * * *$

$2.613 * * *$

$2.875 * * *$

$2.755^{* * * *}$

(0.256)

(0.367)

(0.377)

(0.519)

$$
\begin{gathered}
2.628 * * * \\
(0.256)
\end{gathered}
$$

$2.530 * * *$

$3.522 * * *$

$3.777 * * *$

$3.676 * * *$

(0.256)

(0.375)

(0.386)

(0.527)

$2.994 * * *$ 
cut6

Constant

Notes. $* * *, * *, *$ denote significance at the $1 \%, 5 \%, 10 \%$ level, robust standard errors in parentheses. Clustered on class level.

Number of tokens invested in risk experiment $(\min =0 ; \max =5)$.

${ }^{\&}$ Number of tokens invested in time experiment $(\min =0 ; \max =5)$.

$\$$ The IQ was measured relative to the respective grade (values above 1 indicate above average IQ in the respective grade; values below 1 indicate below average IQ)

${ }^{\S}$ For a detailed description of these variables see the notes on "Parents' estimated income and education" in the Appendix. We did not get information about parents' professions for all children. Hence, the sample size is smaller when this variable is included as independent variable, yet the main results remain unchanged. 
Figure 1: Frequency of donations across age groups.

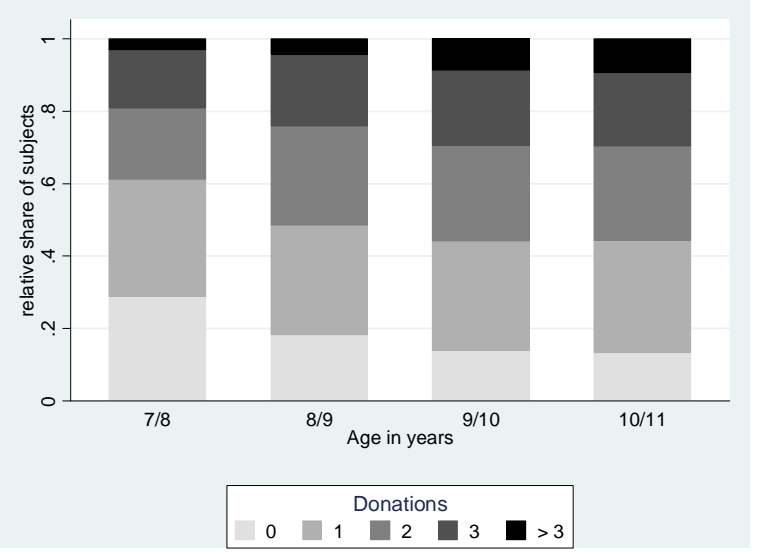


Figure 2: Share of donations conditional on the decisions in the risk (a) respectively time task (b).

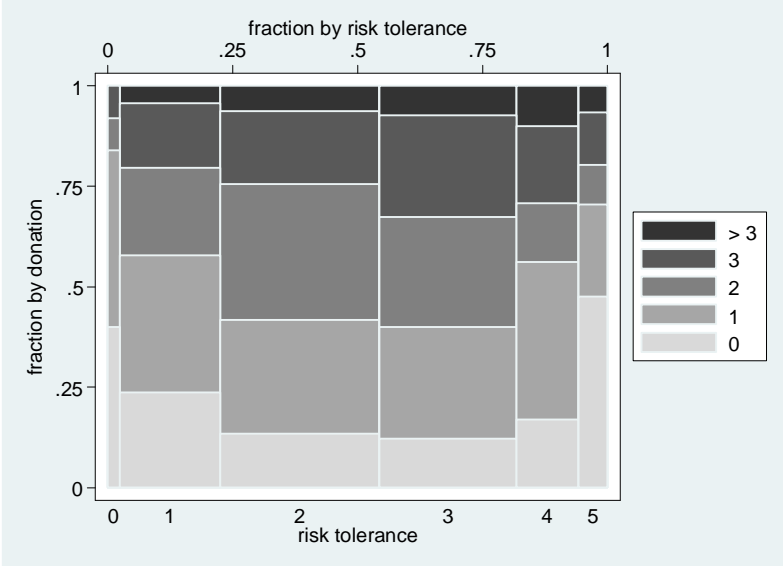

(a)

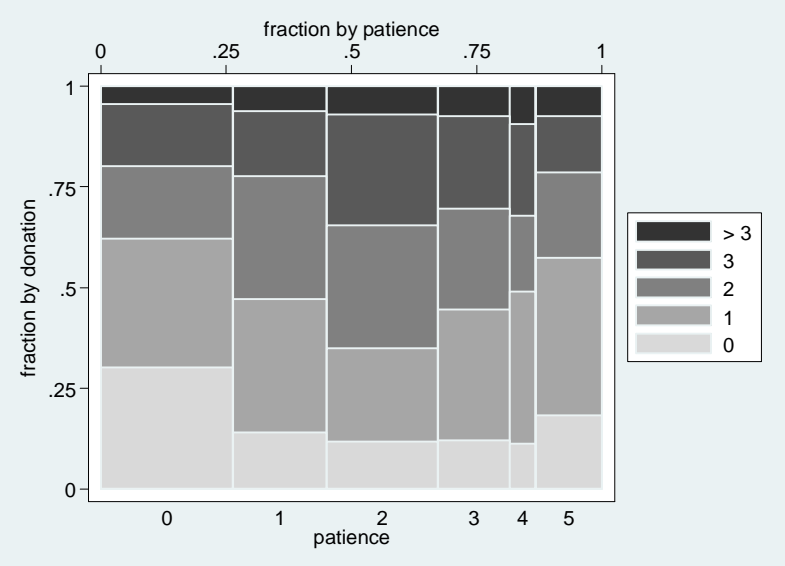

(b) 
Figure 3: Average donations by age and gender.

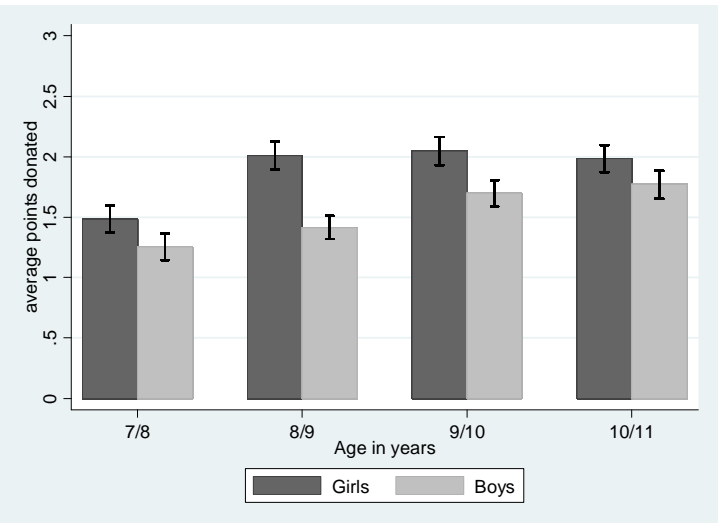

Error bars indicate mean \pm standard error. 


\section{Appendix A1. Notes on estimated income and education of parents}

\section{Estimated income}

In order to get a measure for income we asked the children to state their parent's profession as precisely as possible. The children's answers were categorized with the use of the Public Employment Service Austria (AMS). They provide information on the average gross starting salary per month of almost 1,800 different types of professions. If a child could only give information on the company the parent works at, we used the most common profession within the same company. We used the Austrian Public Employment Service (AMS) classification because the information provided there on different types of professions is much more detailed than the information provided by the census bureau in South Tyrol (ASTAT). However, the average gross starting salary provided by both the AMS and the ASTAT have a highly significant positive correlation. Note that we did not get information about parents' professions for all children participating in our experiment.

\section{Education}

In addition to the average gross starting salary the Public Employment Service Austria (AMS) provides information on the minimum level of education necessary to pursue a particular profession (see http://www.berufslexikon.at/):

1. Other occupations ("Sonstige Berufe"):

This form of education is appropriate for subjects who have already completed another education (apprenticeship or high school degree) but want to start a new profession or for subjects who want to pursue an occupation where no other form of education exists.

2. Apprenticeship ("Lehre”):

Prerequisite: graduation from 9 years compulsory school (at age 15) and holding of an apprenticeship position. The duration of the latter varies between 2 and 4 years depending on the type of profession.

\section{Middle/High school ("Schule"):}

Prerequisite: graduation from 8 years compulsory school (at age 14); plus 4-5 years of middle and high school with a school leaving examination (which qualifies students for entering higher education).

4. University (,Universität, Fachhochschule, Pädagogische Hochschule“):

Prerequisite: higher education entrance qualification. Degrees: Bachelor, Master and Doctorate. 


\section{Appendix A2. Experimental instructions (translated from German/Italian)}

Note: Italic font is used for the instructions to the experimenter.

\section{Donation Game}

This game works as follows:

At the beginning you will receive 6 tokens (put tokens in front of the child). You have to decide how many tokens you want to keep for yourself and how many you want to put in the donation box over there (point at the box in the middle of the room). The tokens you keep for yourself you can exchange into presents in our shop. The tokens you put in the donation box will be given to poor children here in South Tyrol. We calculated how much money a token in our shop is worth and the money, which we collect with the donated tokens, will be given to Caritas South Tyrol (point at the logo of caritas). Do you know Caritas? (Record the answer) Caritas will give the money to poor children in South Tyrol, whose families have little money at home. With the money from Caritas, the parents are able to buy important things such as warm clothes and school things for the children. You can now decide whether you want to donate none, one, 2, 3, 4, 5 or all of your tokens. Please put the tokens, which you want to keep for yourself, in this grey envelope and seal it (put grey envelope in front of child). Please put the tokens, which you want to donate to the children, in this white envelope and seal it (put white envelope in front of child). Even if you put all the tokens in just one envelope you have to seal both envelopes. While you make your decision, I will turn around so that you are completely undisturbed. Please let me know, when you are done. You can then put the white envelope in the donation box over there. It is really important, that no other child ever knows how many tokens you donated and how much you kept for yourself. Can you tell me in which envelope you have to put the tokens you want to keep for yourself? (Answer: grey envelope). And in which envelope do you have to put the tokens you want to donate? (Answer: white envelope). Please make your decision now. Take as much time as you need for your decision and let me know when you are done. (Turn around so that you really cannot see the child anymore. Turn back when child is done. After the decision: check whether the envelopes are really sealed; WRITE THE CODE ON THE GREY ENVELOPE; DO NOT WRITE THE CODE ON THE WHITE ENVELOPE) 


\section{Intertemporal choice experiment}

Good morning. My name is ... Today's game works as follows:

At the beginning you will receive 5 tokens (please place the 5 tokens in front of the child). You have to decide how many of these 5 tokens you want to put in the box labeled NOW (point at the left box) and how many tokens you want to put in the box labeled " 4 WEEKS" (point at the right box). You will receive the tokens that you put in the box "NOW" immediately after the game and you can use these tokens for buying presents in our present shop. You can take these presents home today. Each token that you put in the box "4 WEEKS" will be doubled and you will receive the presents that you choose with these tokens in 4 weeks only.

Let's consider an example: If you, for instance, want to receive two tokens today, what do you have to do? (Answer of the child: "I have to put 2 tokens in the left box) And what happens with the other 3 tokens? (Answer: I have to put these tokens in the right box"; please let the child demonstrate this) How many tokens will be added to this box? (point at the right box; answer of the child: "3"; please demonstrate!) How many tokens are in the box in total? (Answer: 6). When will you receive the presents which you can choose with these 6 tokens? (Answer: in 4 weeks). And what happens if you put 5 tokens in that box? (point at the left box; Answer: then I will receive 5 tokens immediately after the game and I can choose presents with these 5 tokens which I can take home today). And what happens if you put all 5 tokens in that box? (point at the right box; Answer: then these tokens will be doubled and I can choose presents with the 10 tokens which I will receive only in 4 weeks.) Could you please repeat the rules of the game?

Please take your decision now. You have to put the tokens which you want to receive today in this box (point at the left box) and the tokens with which you can buy presents which you will receive in 4 weeks in that box (point at the right box). Take as much time as you need for your decision. In the meantime I will turn around so I don't disturb you. Just call me when you are done. 
Decision sheet for the intertemporal choice experiment (translated form German/Italian)

NOW

4 WEEKS
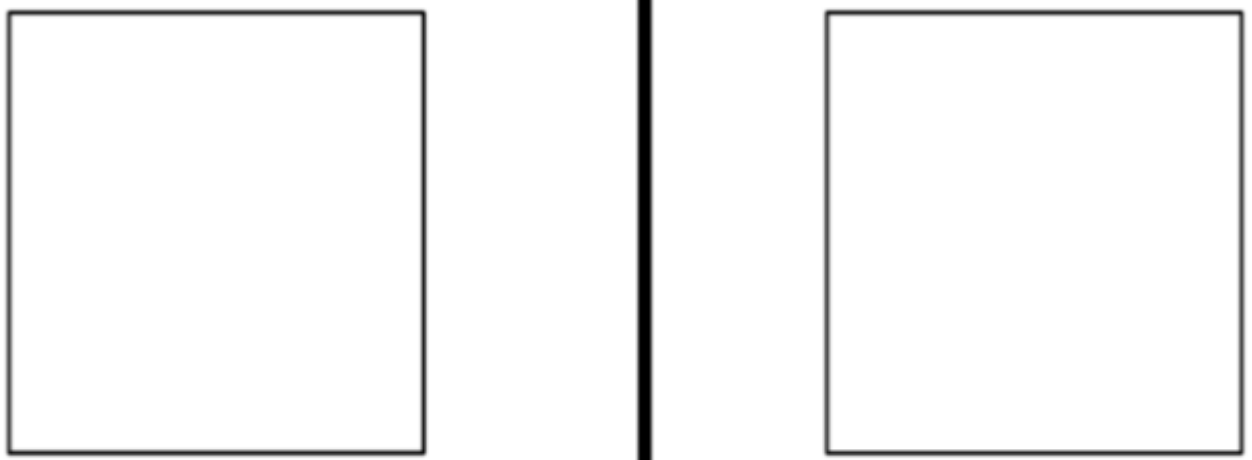


\section{Risk experiment}

Good morning. My name is ... Today's game works as follows:

At the beginning you will receive 5 tokens (please place the 5 tokens in front of the child). You have to decide how many of these 5 tokens you want to keep for sure and with how many of these tokens you want to play the "treasure"-game. You have to put the tokens you keep for sure in this box (point at the left box). Likewise, you must put the tokens with which you want to play the treasure-game in that box (point at the right box). Each token that you put in the treasure-game will be doubled. The rules of the treasure-game are as follows: Here I have two cards. On this card you see a full treasure chest and on the other card there is an empty treasure chest (show the respective cards). I will mingle the two cards under the table and then I will put the cards on the table upside down (please demonstrate; Attention: you have to mingle the cards, such that the child is not able to see the picture on the respective card). Then you can draw one of the cards. If you, for example, draw the full treasure chest, (point at the full treasure chest on the decision sheet), then you will receive all the tokens from this box. On the other hand, if you draw the empty treasure chest (point at the empty treasure chest on the decision sheet) then you will lose all the tokens from this box. At the end you will receive the tokens that you keep for sure (point at the left box) and the tokens that you win in the treasure game (point at the right box).

Let's consider an example: If you, for instance, want to keep one token for sure and play the treasure-game with the other 4 tokens, what do you have to do? (Answer of the child: "I have to put 1 token in the left box and 4 tokens in the right box"; please let the child demonstrate this) How many tokens will be added to this box? (point at the right box; answer of the child: "4"; please demonstrate!) What happens next? How does the treasure-game work? (Child has to repeat the rules of the game). How many tokens will you win if you draw the full treasure chest? (Answer of the child: "8 tokens"). And how many tokens will you receive in total? (Answer of the child: “9”). Exactly. You will receive 8 tokens from the treasure-game plus 1 additional token which you kept for sure. What happens if you draw the empty treasure chest? (Answer of the child: "I lose all the tokens of the treasure-game") Exactly. How many tokens will you receive in total? (Answer of the child: "l”) Exactly. This was only an example. Let's consider another example: Could you please explain the rules of the game if you want to keep 4 tokens for sure and play the treasure-game with 1 token? (The child has to recapitulate the game with the new example). What happens if you, for instance, put all your 5 tokens in this box? (point at the right box; let the child recapitulate the game) What happens 
if you, for instance, put all your 5 tokens in this box? (point at the left box; let the child recapitulate the game). Could you please repeat the rules of the game?

Please take your decision now. You have to put the tokens which you want to keep for sure in this box (point at the left box) and the tokens with which you want to play the treasure-game have to be put in that box (point at the right box). Take as much time as you need for your decision. In the meantime I will turn around so I don't disturb you. Just call me when you are done. 
Decision sheet for the risk experiment

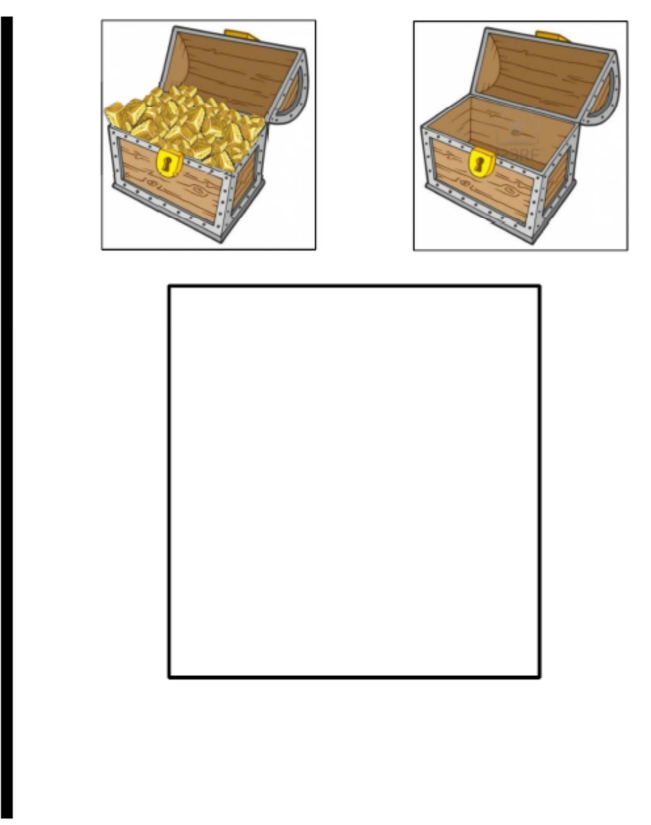

